\title{
Costumes e Justiça: a interpretação da norma no cabildo de Corrientes - 1588 a 1646
}

\author{
Liz Araujo Martins ${ }^{1}$
}

\section{Resumo}

Esse texto foi desenvolvido pelo resultado de um projeto de pesquisa, financiado pela FAPESP. A proposta do projeto era ler e analisar as Actas Capitulares da cidade de Corrientes (1588 a 1646). A análise se fez com o propósito de investigar as leis e sua aplicação nesta cidade, tomando como hipótese as reflexões desenvolvidas pelo professor Rafael Ruiz ${ }^{2}$, em seu projeto "Direitos e Justiça nas Américas". Tais reflexões consistem na idéia de que as leis na América Ibérica do século XVII eram heterogêneas e flexíveis, estavam sujeitas a adaptações, a especificidades circunstanciais e a demandas locais.

Palavras chave: América colonial, costumes, justiça

\section{Introdução}

O projeto de pesquisa que desenvolvi durante ano de 2010, com auxílio da FAPESP, de título Costumes e Justiça na Cidade de Corrientes: séculos XVI e XVII (1588 a 1646) é parte de um núcleo de pesquisa que pretende pensar o Direito na América Ibérica no século XVII. Esse grupo está sob a orientação do professor Rafael Ruiz, do departamento de história da Unifesp, cujo projeto "Direito

\footnotetext{
${ }^{1}$ Graduanda em História pela Universidade Federal de São Paulo e integrante do "Núcleo de Estudos Ibéricos".

${ }^{2}$ Professor do Departamento de História da Escola de Filosofia, Letras e Ciências Humanas - UNIFESP
} 
e Justiça nas Américas" estabelece a hipótese que norteia os trabalhos. Tal premissa sugere que as leis que regiam e administravam nesse período não apenas eram formuladas e promulgadas a partir de costumes como eram aplicadas de acordo com cada caso concreto. De maneira que a aplicação da justiça não estava no cumprimento estrito da lei, mas sim na sua adaptação ou revogação, conveniente a cada situação específica.

A partir dessa hipótese, vários documentos já foram estudados por este grupo de alunos. Alguns deles são: as Atas da Câmara Municipal do Rio de Janeiro e de São Paulo, os Regimentos do Rio de Janeiro e as Atas do Cabildo de Asunción e de Corrientes as quais foram divididas em dois períodos; além de outros documentos e pesquisas que ainda estão em curso.

\section{O Cabildo de Corrientes}

O trabalho que realizei dentro deste núcleo foi a leitura e fichamento das Actas Capitulares de Corrientes, cidade da Região do Prata, do ano 1588 a 1646, documentos reunidos numa publicação da Academia Nacional de Historia (Buenos Aires, 1941). Meu objetivo foi analisar as Atas, a partir da hipótese mencionada, e compreender o funcionamento da administração dessa cidade. Nos cinqüenta e oito anos, referentes a esse conjunto de documentos, pude verificar uma série de questões e situações do cabildo de Corrientes que, assim como os demais trabalhos 
desenvolvidos pelo grupo, contemplam o que temos pensado a respeito do projeto colonial na América.

A província de Corrientes, chamada "Cidade de Vera", foi fundada em 1588 pelo adelantado Juan de Vera y Aragon. O estabelecimento da província tinha pretensão estratégica por sua localização geográfica que além de ligar as cidades de Asunción, Santa Fe e Buenos Aires, ofereciam pontos para possível construção de portos (CAÑEDO-ARGÜELLES, 1988). O testemunho de fundação da cidade, registrado por seu fundador, avaliava que a cidade parecia ser boa para se plantar, oferecia rios para pesca e muita terra a ser repartida. Entretanto, se fazia a ressalva de que se houvesse protestação sobre tais vantagens a cidade poderia ser transferida para outra região, portando o mesmo nome, se assim decidisse o Cabildo (Ata, 1588). Essa instituição administrativa, com tal poder e autonomia, é centro da análise das atas da cidade de Corrientes.

O Cabildo era uma organização administrativa que, dentro da estrutura governamental do sistema de colonização espanhola, prestava contas à sede da governação que, neste caso, inicialmente localizava-se em Asunción. Era formado por doze homens aos quais se atribuíam as funções de alcaldes, regedores, procurador geral, mayordomo e escrivão, acima dessas funções estava a autoridade do 
Tenente de governador, nomeado pelo governador que o designava como "justiça maior da cidade".

A primeira formação do Cabildo de Corrientes foi realizada por seu fundador que nomeou os seus integrantes e assumiu o posto de Tenente de governador. Segundo a designação da carta de fundação, o mandato de cada integrante, à exceção do Tenente, deveria ser de um ano. Expirado tal período os integrantes ainda vigentes nomeariam os seguintes. A data das eleições era sempre dia primeiro de Janeiro. Pela avaliação da praxe do Cabildo pude perceber sua significativa força e liberdade de decisão nos mais diversos assuntos e situações. Segundo a autora Teresa Cañedo-Argüelles, tal autonomia era favorecida pela localização da cidade que, apesar da ligação com outras três cidades, estava ilhada pelos rios. A dificuldade de acesso à cidade lhe permitia, portanto, fazer deliberações mais independentes.

Entretanto, outro aspecto me parece um fator importante dessa autonomia do Cabildo. Trata-se justamente de um sistema de governo que previa a avaliação autônoma de seus administradores e juízes que, ante as muitas possibilidades de demandas e situações particulares da empreitada da colonização, provavelmente teriam que fazer escolhas e acomodações daquilo que fosse ordenado pelas instâncias superiores por meio das Provisões, Petições ou Cédulas Reais. Como mencionado inicialmente, o que temos pensado é que 
a havia um espaço para avaliação das possibilidades. Neste espaço estava a autonomia dos governantes da cidade.

A autonomia cedida ao Cabildo, registrada no seu testemunho de fundação, é o caráter de seu sistema administrativo. Juan de Vera y Aragon fez a nomeação dos primeiros cabildantes destacando o dever desses oficiais de guardar e conservar a cidade administrando justiça nas questões civis e criminais conforme as Cédulas e Ordenanças Reais sobre as cidades das Índias. Os próprios cabildantes deveriam eleger seus sucessores "por votos debaxo juramento conforme dios mejor les diere a entender en sus conciencias nonbramdo aquellas personas que com mas rectud y zelo entendieren que conbiene el servicio de dios y de su magestad para el buen governo de la dicha civdad como se hace en los reynos del piru y en todas las yndias ${ }^{3,}$

Essa citação faz referência a aspectos da lógica política desse contexto muito importantes para a reflexão deste texto. $\mathrm{O}$ primeiro desses aspectos que gostaria de destacar é o procedimento de eleição cuja realização era promovida pelos votos dos próprios membros do Cabildo. Apenas o Tenente de Governador era nomeado pelo próprio Governador, entretanto nas demais funções, salvo raras exceções, as instâncias superiores da hierarquia administrativa não intervinham na eleição dos membros do Cabildo.

${ }^{3}$ Testemunho de Fundação, 1588. Academia Nacional de la Historia, 1941. 
A implicação desse sistema eleitoral foi a formação de um órgão político administrativo e jurídico, formado por um grupo de homens que permutaram nos cargos no Cabildo durante muitos anos ${ }^{4}$. Desse ponto, uma primeira constatação que se poderia tirar é que o Cabildo de Corrientes era um grupo enraizado, que, conseqüentemente, teria considerável força política.

Entretanto a força dessa instituição não estava exatamente no seu caráter arraigado, mas sim na própria autonomia administrativa e jurídica que lhe era concedida. No Testemunho de fundação referido, é dada ao Cabildo a autoridade de, em nome do rei, transpor a cidade se assim julgasse útil aos povoadores. Esse julgamento em favor do que fosse bom e útil a Republica ${ }^{5}$ era o critério com o qual deliberava o Cabildo. A expressão, "para o bem e utilidade da República" aparece em praticamente todas as decisões, e pareceres do Cabildo, seu uso - me parece - não se tratava de mera formalidade, mas sim de um efetivo princípio de julgamento com o qual o Cabildo "fazia justiça". A idéia de bem e utilidade da República referia-se ao que fosse bom para o rei e seu reino, não se tratava de bem comum como a idéia atual de bem estar

\footnotetext{
${ }^{4}$ Pelo menos durante os cinqüenta e oito anos referentes à documentação que tive acesso, pude verificar que o Cabildo foi formado num processo de revezamento dentro de um grupo. Os que saíam ficavam fora por um intervalo de um ou dois anos até novamente serem eleitos.

${ }^{5}$ República é exatamente o termo que aparece na Ata para referir-se não só a cidade de Corrientes, mas também a todo domínio espanhol.
} 
político, social e econômico, mas sim uma referência ao que fosse do interesse do soberano, da prosperidade de seu reino e do bem dos seus súditos.

O Cabildo era, portanto uma instituição com força de decisão e execução do fosse justo, útil e bom para a República. Desse ponto decorre o segundo aspecto que gostaria de refletir a partir da citação: Para que se fizesse "bom governo", era preciso eleger, bons governantes. A escolha desses governantes deveria ser motivada por algo transcendente, era Deus quem lhes daria a entender em suas consciências o que fosse mais conveniente ao seu próprio serviço e ao rei. O princípio norteador era, portanto a Religião - cristã católica -, mas a decisão do que fosse conveniente era uma questão da consciência de cada membro do Cabildo.

O último e mais sutil ponto que quero destacar no Testemunho do fundador de Corrientes é que a sua determinação do que deveria ser feito quanto às eleições e seus critérios, nada mais era do que aquilo que se fazia em todas as cidades das índias, ou seja, havia em todo domínio espanhol Cabildos com força política, autoridade jurídica e autonomia interpretativa do que fosse conveniente a Republica e ao "bom governo" 6 . Esses aspectos, que poderiam soar como elementos de homogeneidade eram de fato de

\footnotetext{
6 "Bom governo" é outra expressão que assim como "para o bem e utilidade da República" era usada para justificar as decisões do Cabildo.
} 


\section{Cadernos de Clio, Curitiba, n. ${ }^{\circ}$ 3, 2012}

diversificação. Justamente por causa dessa lógica eleitoral e deliberativa - dos reinos do Peru e das províncias das índias - cada Cabildo tinha uma especificidade, não apenas pelas localidades diferentes, mas, sobretudo por causa da autonomia nas deliberações e funcionamento político.

O historiador Constantino Bayle, na obra "Los Cabildos Seculares en la América Española", faz a seguinte definição da instituição Cabildo: "Se cifra en administrar justicia y ordenar lo conducente al pro comum; o como dice Santayana, gobierno político y económico, el cual es tan privativamente de los Ayuntamientos o de los Consejos de ellos que, no habiendo queja de parte, o instancia fiscal, no peuden las Chancerías o Audiencias entrometerse en estos asuntos." (1952). Ao fazer essa descrição do caráter político do Cabildo o autor menciona um de seus limites, as Audiências. Esse ponto é importante porque ajuda a fixar o que estou chamando de autonomia do Cabildo, pois não se trata de uma instituição independente, fora de um sistema administrativo, estou tentando descrever uma instituição política que tem a liberdade de deliberar aquilo que, a critério de sua análise ou parecer, for conveniente e justo.

$\mathrm{Na}$ obra "La província de Corrientes: un modelo de Colonizacion en El Alto Paraná", Teresa Cañedo-Argüelles, questiona sobre o modelo hispânico estabelecido na América. A 
autora diz que tal modelo na verdade era o modelo da adaptação. Ela menciona o autor George Foster que denomina esse modelo como "cultura de conquista", ou seja, tratava-se da cultura indiana, colonial formada no processo de contato com os habitantes da América que provocaram as iniciativas espontâneas dos conquistadores.

Cañedo-Argüelles explica que após a dominação do território o segundo passo era por em prática os mecanismo de colonização, ou seja, estabelecer normas de funcionamento político e jurídico. Segundo autora, no caso do Paraguai e do Rio da Prata essa empreitada pelo estabelecimento de um Sistema político significou setenta anos de tensão entre o costume e norma. Ainda que a norma tenha prevalecido em termos jurídicos, a autora afirma que é preciso considerar em justa medida o sedimento que o costume deixou no temperamento social daquela região.

Segundo Cañedo-Argüelles foi nesse contexto de oficialização da norma sobre o costume que se deu o fundamento da cidade de Corrientes. A argumentação da autora é que os conquistadores fundadores da cidade buscaram atender com fidelidade à cultura peninsular hispânica porque queriam ser reconhecidos como espanhóis e não como mestiços. Por isso, diferentemente do que era costume em Asunción o grupo que iniciou o processo de povoamento em Corrientes não se unia às 
mulheres dos grupos indígenas daquela região ${ }^{7}$. A autora não faz ressalvas sobre esse aspecto, entretanto me parece que não é sua intenção afirmar que tais uniões jamais ocorressem, mas sim que quando ocorriam não eram assumidas como era costume em Asunción onde os espanhóis não apenas se uniam às mulheres índias como orgulhosamente reconheciam os descendentes dessas uniões.

Entretanto apesar de Teresa Cañedo-Argüelles entender esse aspecto como indicador de que a especificidade de Corrientes era sobrepor a norma sobre o costume, me parece que a idéia só se aplicaria sobre os assuntos de identidade étnica, visto que a própria autora considera que tanto o aspecto econômico quanto o administrativo não correspondiam aos padrões peninsulares. Esse parecer da autora é fundamental, pois vai ao encontro do que pude observar nas documentações que analisei as quais também foram utilizadas pela autora. O trabalho de Teresa Cañedo-Argüelles é muito mais amplo e contou com um arsenal documental muito mais volumoso que esta pesquisa que realizei, portanto é imprescindível às reflexões desenvolvidas aqui os pressupostos sobre a cultura administrativa de Corrientes que a obra da autora fornece.

A autora afirma que "los patrones peninsulares sufrieron un proceso de transformación de acuerdo con las circunstancias

\footnotetext{
${ }^{7}$ De acordo com Teresa Cañedo-Argüelles, essas uniões entre espanhóis e índias eram ilícitas.
} 
impuestas por el contacto que obligaron, (...), al desarollo de un organismo capitular muy sui géneris y de unas tácticas defensivas y policiales acordes con la características de los obstáculos geográficos y humanos que se presentaban." O que gostaria de acrescentar às reflexões da autora sobre as adaptações e transformações conforme às circunstancias é que tais adaptações era um modo de proceder que era previsto pelo projeto colonial e que as adaptações administrativas e jurídicas da norma era propriamente o caráter do sistema. Em outras palavras, quero pontuar que as normas eram sempre sujeitas não apenas ao costume, mas também ao parecer e interpretação dos juízes, membros do Cabildo.

\section{Autonomia e costume}

No ano de 1638 o governador solicitou ao Cabildo que enviasse quinze soldados em socorro a uma cidade na Região do Uruguai, especificamente numa redução jesuíta, que estava sendo assolada pelos índios guayacurus. O Cabildo protestou veementemente à ordem argumentando que não possuíam soldados nem armas para prestar esse socorro. Além disso, os cabildantes disseram temer o mesmo fim da cidade de Rio Bermejo, que havia sido praticamente despovoada pelos ataques indígenas. A resposta do governador ao Cabildo foi que deixaria a decisão de acatar ou não ao pedido de socorro, a cargo do Tenente de governador 


\section{Cadernos de Clio, Curitiba, n. ${ }^{\circ}$ 3, 2012}

Nicolas de Villanueva, dizendo remeter a Villanueva o que fosse conveniente a partir do requerimento dos capitulares.

O Tenente então decidiu seguir a ordem, argumentado que sempre procurou obedecer com pontualidade o que mandava o governador. Os soldados foram enviados, sob muitos protestos, e pouco tempo depois o Cabildo exigiu o retorno deles bem como dos índios que haviam sido enviados; além de prescrever que a responsabilidade das mortes de alguns desses homens caísse sobre o Tenente Nicolas de Villanueva. Uma carta de comunicação dessa decisão foi enviada pelo Cabildo ao governador. (Ata, 1638)

Esse exemplo é bastante significativo. O primeiro aspecto importante refere-se à fluidez da hierarquia dentro dessa organização. O Tenente de governador era a maior autoridade local e acima dele estava o governador. No entanto, a ordem vinda da instância maior é revogada e a resposta do governador é o consentimento de colocar a cargo da "justiça maior" (o Tenente) o que for conveniente. Ainda assim, a decisão que prevaleceu foi a do Cabildo, a última instância da hierarquia. $\mathrm{O}$ segundo aspecto referese à maleabilidade da própria ordem, a qual foi transgredida justamente por ter sido submetida à decisão de um único homem que por sua vez deveria considerar o que foi argumentado pelo Cabildo. Essa consideração abriu o espaço que permitiu que a deliberação do Tenente fosse transgredida pelo Cabildo. 
A margem para a transgressão da lei, mencionada nesse exemplo, decorre de um ponto da análise muito importante acerca dos procedimentos do Cabildo, trata-se da força do costume. Como muitos autores já explanaram ${ }^{8}$, em Corrientes e nas demais regiões coloniais da América, muitas vezes fazia-se a lei a partir dos costumes locais. A conseqüência direta desse procedimento é um sistema de leis heterogêneas, uma vez que os costumes se desenvolviam nos processos particulares de cada região e, portanto tinha força no local específico onde determinado costume era vigente. No caso desta pesquisa, a delimitação do período se refere a uma província nos primeiros anos de sua formação. Portanto os costumes locais ainda estavam sendo moldados às demandas da consolidação da cidade e influenciados pelos hábitos e pareceres de seus fundadores.

Entretanto, o costume a que me refiro aqui não são simplesmente hábitos enraizados, mas sim a cultura local que contava: com os interesses dos membros do Cabildo, com as necessidades materiais - pois se tratava de uma cidade pequena e ilhada - com a população indígena - seus interesses e resistências -

\footnotetext{
${ }^{8}$ Dentre as muitas produções sobre o tema, há um artigo de Carlos Zeron e Rafael Ruiz que é uma referências para os estudo que tenho desenvolvido trata-se de "La fuerza de la costumbre, en la capitanía de São Paulo, de acuerdo con la Apologia pro Paulistis (1684)”. In: Perla Chichilla, Antonella Romano. (Org.). Escrituras de la Modernidad: los jesuitas entre cultura retórica y cultura científica. México: ed. Universidad Iberoamericana/ ed. Ecole des Hautes Etudes en Sciences Sociales, 2008, p. 271-302.
} 
com os interesses da Companhia de Jesus e padres franciscanos locais, além dos interesses dos governadores da região que tinham que lidar com essa cidade por meio de intervenções que às vezes eram aceitas e outras vezes não.

Como mencionado anteriormente, Teresa CañedoArgüelles, afirma que a particularidade da cidade de Corrientes consistiu na tentativa de resolver essa tensão entre norma e costume justamente obedecendo-se às normas. Contudo a autora faz ressalva de certas adaptações da lei por causa dos costumes locais. É exatamente sobre essas adaptações que debruçamos nossa atenção, pois o que temos afirmado é que o arbítrio de se fazer várias interpretações da lei não é exceção, mas sim regra.

Um exemplo dessa adaptação da lei em Corrientes é a que se refere às eleições do Cabildo. De acordo com a Provisão Real os integrantes do Cabildo não poderiam ser parentes entre si. Contudo, já no ano da fundação da cidade há um pedido dos capitulares a Real Audiência de que se reformasse a norma estabelecida pelo rei. Os capitulares pediram tal reformulação em favor do tenente de governador Alonso de Vera y Aragon que havia recebido seu título pela autoridade de seu tio, o fundador da cidade.

Não há registro da resposta da Real Audiência a esse pedido. O que há registrado é que tal norma foi acatada em certas ocasiões, mas também foi transgredida em muitas outras. Chama a 
atenção, nesse exemplo, que no cumprimento ou não dessa lei, havia uma preocupação dos capitulares a sempre fazer referência a ela colocando-a sob uma verificação da sua conveniência em cada situação. Os argumentos para o não cumprimento da lei podiam ser de ordem moral, como referir-se ao caráter do tenente em questão, ou de ordem prática como a necessidade de conservar um determinado tenente que estava atuando em algum conflito com grupos indígenas. $\mathrm{O}$ que procuro destacar nos registros é o reconhecimento, por parte dos capitulares, da autoridade real ao mesmo tempo em que há a transgressão da norma estabelecida por conta da circunstância real.

Assim como esse exemplo, há outros referentes à promulgação e aplicação de leis que também se faziam a partir de situações específicas. Como no caso de uma lei formulada pelo fundador da cidade que previa uma punição absolutamente severa a quem ousasse sair da cidade sem autorização. As atas registram que tal norma foi posta por ocasião de certo capitão querer ausentar-se da cidade. Os termos da lei eram gerais, entretanto direcionava-se a apenas um indivíduo, pois à exceção deste capitão, tal norma jamais foi si quer referenciada. Quando se quis vetar a saída da população, em lugar de invocar a lei que fora estabelecida, os governantes apenas fizeram o apelo de que ausentar-se da cidade poderia deixála vulnerável. (Carta de instrução, 1588) 
A idéia de heterogeneidade da lei que tento desenvolver a partir desses exemplos, refere-se a três aspectos: primeiro, a transgressão era justificada por questões e motivos externos à norma - interesses individuais e coletivos, demandas etc.. Segundo, as leis podiam ser feitas tanto com o propósito de normatização da vida coletiva, como para limitar ou direcionar um único indivíduo. Terceiro, as leis régias ou as determinações dos governadores não tinham a mesma força em todas as localidades; a força da lei estava no seu cumprimento. Cumprir a lei dependia da decisão e interesse dos cabildantes, que por sua vez deliberavam lidando com o interesse do governador, dos jesuítas, dos grupos indígenas, dos demais povoadores da cidade etc.. Tal caráter fluido das normas trata-se de uma forma de conceber o Direito, isto é, a adaptação da lei não é uma indicação de sublevação ou desordem, tratava-se de um projeto de colonização que pretendia efetivar o Direito a partir de cada caso e não propriamente da lei institucional.

\section{A consciência na interpretação das leis}

Nesse sistema de lei bastante maleável o fator essencial e norteador do arbítrio para efetivação da justiça era a consciência dos governantes e juízes; esta deveria tender ao bem comum e, sobretudo a uma conduta cristã autêntica. As eleições do Cabildo de Corrientes foram realizadas a partir desta lógica e não necessariamente pela norma que regularizava seu processo eleitoral. 
Ao longo dos anos, o Cabildo foi formado por meio de nomeações, sorteio e mesmo por aprovação de chapa formada antecipadamente. Em cada uma dessas ocasiões a consciência foi invocada como critério de procedimento e voto. Juan de Torres de Vera y Aragon, o fundador, ao nomear os primeiros capitulares de Corrientes faz a seguinte declaração:

"Y pareciendome que la dicha elecccion es justa que de aqui en adelante se haga em um dia señalado (...) nombrando los que salieren a los que entraren por voto de bajo juramento conforme a derecho estando en su Cabildo y Ayuntamento como Dios mejor les diera a entender sus conciencias, nombrando aquellas personas que con mas rectitud y celo entendieren que conviene al servicio de Dios e de su magestad para El buen govierno de dicha ciudad" (Ata,1588)

Em outras eleições vê-se a menção ao mesmo critério:

"En Dios y sus conciencias para el buen govierno y aumento desta ciudad, en sevicio de Dios nuestro señor y a su magestad nombraran y elexieron por alcaldes (...)” (Ata, 1592)

"se ayuntaron a Elegir y nombrar las personas que en sus conciencias allan ser mas suficientes para que usen y exercan los oficios de alcaldes y regidores (...) los quales su mrds de sus capitulares allaron por descargo de sus conciencias ser las personas mas 
Cadernos de Clio, Curitiba, n. ${ }^{\circ}$ 3, 2012

abiles vsuficiente para vsar y exercer los dichos oficios de alcalde (...)” (Ata, 1593)

“dixo que en dios y en su conciencia estaba justa acertada la dicha Elecion” (Ata, 1596)

"se haga dos papeles y alli asiente el nombre de que le pareçiere descargando su conciencia." (Ata, 1604)

A cultura cristã católica era a norteadora da consciência dos cabildantes. A concepção de consciência neste estudo, portanto seria o efeito que a moral cristã podia causar no indivíduo a ponto de constrangê-lo a uma determinada conduta. Alguns autores já fizeram menção à força da consciência. O historiador Bruno Feitler faz referência a esta questão em sua obra Nas Malhas da Consciência: Igreja e Inquisição no Brasil - nordeste 1640 -1750 apontando o papel fundamental da denúncia para o Santo Ofício. A denúncia era incentivada pela instituição através do apelo às pessoas para que descarregassem suas consciências denunciando aqueles que estavam em conduta de pecado, pois a omissão os colocaria na mesma condição de pecadores e, conseqüentemente, sujeitos a mesma punição ou mesmo condenação eterna.

O autor ainda explica que uma das dimensões políticas do pecado era o escândalo cujo efeito era o comprometimento da salvação de toda a comunidade além da confrontação da autoridade da instituição repressora. Em suma, a consciência livre da acusação 
do pecado e, a partir dela, a concretização da salvação da sociedade - ou "o bem da República" - era efetivamente um fator de procedimento e de estabelecimento da justiça.

\section{O autor Paolo Prodi aprofunda o assunto em "Uma} história da justiça" (2005). A premissa do autor diz que existe uma tradição do Direito Ocidental cristão a qual consiste numa dialética histórica entre foro externo e foro interno, em que o primeiro é exercido pelo juiz ou instituição e o segundo pelo próprio juízo exercido pela culpa. Esse foro interno diz respeito à consciência que, no caso, estará sob o julgamento do confessor. A idéia do autor é enfatizar a fluidez da fronteira entre foro secular e foro eclesiástico até o século XVIII; não se trata apenas de um poder sobre o outro, mas de uma dualidade, de uma constante tensão entre as duas instâncias. Ambas têm em comum o poder de coerção.

\section{Richard Morse em "O espelho de Próspero" (1988),} também destaca a consciência como um determinante do Direito Ibérico e aponta a escolástica como origem dessa concepção. Morse diz que de acordo com as postulações de Pedro Abelardo (1079 1142) a desobediência estava na intencionalidade e não na ação em si, ou seja, a consciência como motivadora da prática era o que determinava se alguém estava pecando ou não nas suas atitudes, deliberações ou coerções. Em Corrientes, verificamos que o efeito da instância moral dava à consciência o poder de interpretar a lei e 
usá-la de maneira que fosse conveniente à justiça, ou seja, ao cumprimento dos princípios cristãos e do rei, o ungido de Deus.

Essa forma de pensar era componente da cultura moral desses homens de Corrientes. É a partir dela que os cabildantes respondem à Petição Real que exigia o pagamento da media anata (tipo de imposto). Como cumprimento de tal ordem, os capitulares formularam a seguintes resposta:

“Estando tratando algunas cosas conbinientes a esta republica acordaran que se vean las petticiones que prezento el procurador general y enquanto a la una que es en razon de la sup.ca sobre la media anata drs de su magestad que no a lugar atento a estar resevido en la causa desta provincia que asi se guarde y cumpla como y de la manera que se contiene y se de cuenta en lo mas por quanto en esta ciudad por ser tan pobre na ay offo.s exsamindaos $n i$ tienda, proprietários de of.o ningun sino que cada qual travaja en sus menesteres en todo aquello que an menester de ynjenio (...) En lo demas seprovea el auto que convenga para que tenfa efeto La cobransa como su mag.a manda desde el dho año y en esto setenga el cuidado que conbenga al real servisio" (Ata, 1635)

Está claro nesse registro a reverência ante a ordem Real. Contudo, há também a abertura de um espaço que permite que o 
cumprimento dela esteja sempre inclinado a considerar situação de pobreza dos habitantes e dos órgãos administrativos da cidade. $\mathrm{Ou}$ seja, pede-se que o bem comum seja considerado. Esse espaço de negociação da norma é um dos elementos que temos avaliado no sistema jurídico da América Ibérica. Para entender melhor os mecanismos desse sistema e compreender o papel da consciência nas deliberações tanto dos administradores quanto dos juízes (alcaldes), é necessários verificar alguns princípios de teorias jurídicas do período, bastante influentes nesse sistema, como é caso do probabilismo.

O probabilismo foi uma doutrina que inicialmente referiase a questões de âmbito moral, elaborada por Bartolomeu de Medina e captada pelo âmbito jurídico por Jean Gerson -1363 -1429 (RUIZ, 2010). Grosso modo, tal doutrina previa que uma determinada questão poderia ter várias soluções prováveis e que nesse campo de possibilidades agia prudentemente aquele que seguia uma das possibilidades. Um segundo princípio diz que a lei dúbia não é lei, ou seja, a lei dúbia não poderia ter força de obrigar, pois estaria sujeita a muitas interpretações. Entender essa teoria permite compreender que a consciência, neste caso, avalia uma gama de possibilidades. Tais opções poderiam ser mais ou menos assertivas, mas seriam justas à medida que fossem prováveis. 
O fato de essa doutrina jurídica ter sido cooptada pelas elites locais não significava que essas elites tinham necessariamente um conhecimento teórico dela. Assim como Casuísmo, o Probabilismo tratava-se de uma forma de pensamento que fazia parte da cultura social desse período. Os juízes (alcaldes, Tenentes de Governador, Juízes de Residência e cabildantes) deliberavam a partir desse pensamento. O autor Victor Tau Anzoátegui, em sua obra "Casuísmo y Sistema" propõe como reflexão investigar as crenças e idéias do espírito hispano-indiano a partir da atividade judicial. É importante destacar dois pontos da argumentação de Tau Anzoátegui sobre seu objeto de estudo, o casuísmo: o primeiro é que o casuísmo é tomado pelo autor não apenas como mero termo do campo jurídico; sua argumentação é que era uma expressão da mentalidade da sociedade do século XVI a XVIII que se manifestava em outros traços da vida social: na política, economia, filosofia etc. O segundo ponto é que, segundo Tau Anzoátegui, os historiadores geralmente entendem o casuísmo como um Direito Peninsular que se constituiu a partir das especificidades do Novo Mundo, contudo o autor argumenta que se tratava de uma mentalidade de Direito comum ao mundo castelhano.

Tau Anzoátegui mostra como essa forma de pensamento casuísta - estava entranhada na sociedade tanto na América quanto na Península. O casuísmo, como cultura social, consistia na idéia de 
que a justiça estava na decisão adequada a cada situação específica e não no cumprimento da norma. Cada caso deveria ser resolvido não nos termos da lei, mas nos termos de sua própria particularidade. Como apontado nos diversos exemplos, no caso do Cabildo de Corrientes acatar ou não a lei dependia das demandas locais e tais decisões partiam da consciência do que fosse justo e útil à cidade. Assim, poderiam ser várias as interpretações ou opiniões prováveis do fosse bom. Era nesse sentido é que a autonomia do Cabildo de Corrientes se efetivava; valendo-se justamente desse espaço de negociação da lei, os integrantes do Cabildo adaptavam as normas, fossem elas vinda dos governadores ou do próprio rei.

\section{Conclusão}

As particularidades da cidade de $\underline{\text { Corrientes }}$ - configurada por sua recente fundação, pequena população e poucos recursos tinham lugar privilegiado em relação à sistematização da norma; esta era referida e muitas vezes reverenciada, entretanto era condicionada a fatores específicos e a critérios relacionados à consciência cristã dos governantes que formavam o Cabildo. A lei era cumprida nas situações em que acordava com as circunstâncias.

Desde a sua formação, ao Cabildo foi concedida a autonomia de seu funcionamento e mesmo da decisão de consolidar a cidade no local delimitado por seus conquistadores. $\mathrm{O}$ registro da 
relação dos capitulares com a Real Audiência, com o governador e com a autoridade local, o Tenente, além de mostrar essa independência administrativa revela também maleabilidade da hierarquia política na Região do Prata.

Essa estrutura específica foi gerida numa lógica de escolhas políticas motivadas por teorias jurídicas que previam um campo de possibilidades e de contextos particulares. As decisões do Cabildo registradas pelas atas sugerem sempre uma preocupação em seguir o princípio da norma e não necessariamente seus termos. Tal quadro configura uma amostra do sistema jurídico na América Ibérica do século XVII.

\section{Referência Documental}

Actas Capitulares da Corrientes. Tomo I: años 1588 a 1646. Introducción: GOMEZ, Henán F. Buenos Aires: Academia Nacional de la historia, 1941.

\section{Referência bibliográfica}

BAYLE, Constantino. Los Cabildos seculares em la America Española. Madrid: Sapientia, S. A. de Ediciones, 1952 
CAÑEDO-AGUELLES, Teresa. La provincia de Corrientes en los siglos XVI y XVII: Un modelo de colonización en el Alto Paraná. Madrd: C.S.I. C, Centro de Estudios Históricos, Departamento de Historia de América, 1988

FEITLER, Bruno. Nas malhas da consciência: Igreja e Inquisição no Brasil - nordeste 1640 -1750. São Paulo: Phoebus; Alameda, 2007.

MORSE, Richard M., O Espelho de Próspero: cultura e ideias nas Américas. São Paulo: Companhia das Letras, 1988.

PRODI, Paolo. Uma história da justiça: Do pluralismo dos foros ao dualismo moderno entre consciência. São Paulo: Martins Fontes, 2005.

RUIZ, Rafael, Hermenêutica e Justiça na América do século XVII. In: Anais do XXVI Simpósio Nacional de História - ANPUH. São Paulo, julho 2011

- Os espaços da ambiguidade: os poderes locais e a justiça na América do século XVII. Rev. hist. [online]. 2010, n.163, pp. 81-101. ISSN 0034-8309

TAU ANZOÁTEGUI, Victor. Casuísmo y Sistema: Indagación histórica sobre el espíritu del Derecho Indiano. Buenos Aires: Instituto de Investigaciones de Historia del Derecho, 1992. 